\title{
¿FUE ÁNGEL GONZÁLEZ \\ UN POETA POSMODERNO?: \\ EXAMEN DE SU ANTIPOESÍA
}

\author{
Claude Le Bigot
}

Université de Rennes 2 / CELLAM

Hablar de antipoesía para valorar a un poeta que ha merecido un amplio reconocimiento en el panorama de las letras españolas podría resultar poco pertinente, y hasta contraproductivo, a la hora de asomarse a la veta realista que caracteriza parte de la producción del medio siglo pasado. De modo que nos importa definir primero qué es lo que se entiende por «antipoesía». Podemos aducir el hecho de que el propio Ángel González no vaciló en aplicarse a sí mismo tal concepto para hablar de una etapa de su obra que se inicia con Breves acotaciones para una biografía (1971), que se prolonga con Procedimientos narrativos (1972) y se acentúa en Muestra, corregida y aumentada, de algunos procedimientos narrativos $y$ de las actitudes sentimentales que habitualmente comportan (1977). Ángel González escribe en la introducción de una antología suya editada por Cátedra lo siguiente: «En esos títulos, la tendencia al juego y a derivar la ironía hacia un humor que no rehúye el chiste, la frivolización de algunos motivos y el gusto por lo paródico, apuntan hacia una especie de “antipoesía”, en cuyas raíces está cierto rencor frente a las "palabras inútiles"» (González, 1980: 22). Contienen estas palabras una doble enseñanza: primero, anuncia Ángel González una serie de procedimientos (ironía, humor, chiste, frivolización, parodia) que ya eran manifiestos desde la primera etapa y que ahora van cobrando mayor relieve; afectan la tonalidad, configuran una postura de «antipoesía»; y añade que en su raíz puede haber cierto recelo ante los poderes de la palabra poética. Antes de ir más allá merece la pena recordar que la crítica literaria casi no manejó el concepto de «antipoesía» antes del surgimiento de tendencias más actuales nacidas con el realismo sucio de los años 80. A partir de ese momento comienza a generalizarse el empleo de la palabra para designar esta tendencia 
realista que evidentemente va en contra del canon con el cual se solía valorar la producción lírica. Acaso el olvido de lo que fueron las vanguardias de comienzos del siglo XX contribuyó a ocultar aportes que ya significaron un rompimiento de los moldes modernistas a favor de una audacia experimental que afectaba en profundidad el significado poético. En Hispanoamérica, donde perduró más el vanguardismo produciendo una fructífera floración (Larrea, Vallejo, el Neruda residenciario), tuvo retoños tardíos, pero espléndidos, inclinándose hacia vertientes de creatividad insospechada. Prosperó en Chile, Argentina y Brasil la noción de antipoesía descubriendo ínsulas extrañas que se caracterizaron por el rechazo de los modelos canónicos de la poesía. Se suele traer a colación la obra del chileno Nicanor Parra (Poemas y antipoemas, 1954, y Artefactos, 1972) o también la deVicente Huidobro. Se debe a Adolfo Vásquez Rocca un estudio sólido de la obra de Nicanor Parra y sobre todo un esfuerzo por teorizar la «antipoesía». Lo citamos por habernos aclarado las condiciones de aparición del fenómeno:

\begin{abstract}
Una visión tipológica del arte, ahora acotada a la literatura contemporánea, permite observar que los géneros convencionales han perdido estabilidad y se han confundido con otros de naturaleza análoga o diferente, que han aparecido géneros y textos intermedios, confusos, ambiguos, híbridos, y que estos cambios se producen en interacción con géneros y discursos convencionalmente no-literarios (Vásquez Rocca, 2012: 8).
\end{abstract}

Sin llegar a ser un discurso totalmente discontinuo, el que se inventa Ángel González acude a estrategias de parodia y de humor propias de la condición posmoderna. Cosas que antes pudieron ser consideradas como espurias le permiten describir con fidelidad su experiencia de una vida deprimida, con falta de expectativas y poblada con una humanidad zozobrante. El discurso que pone en marcha Ángel González tiene una carga corrosiva indiscutible, pero al mismo tiempo deja aflorar los signos de una estética posmoderna.

Si la posmodernidad literaria surge en un momento de crisis de la representación y acompaña el hundimiento de las ideologías o discursos de legitimación, es también inseparable de la crisis del sujeto y su desconfianza en la racionalidad. El contexto socio-histórico en el que se gestó la poética gonzaliana, especialmente en pleno auge de la poesía social que coincidió con sus primeros poemarios, nunca lo llevó a una aceptación total e incondicional de la instrumentalización en aras de las ideologías izquierdistas. Quiso 
conservar Ángel González una subjetividad autónoma que lo llevó a experimentar otros cauces estéticos alejados de los antagonismos rígidos y simplificadores. En cierta medida, el ambiente moral autoritario y cínico de la sociedad franquista, la mediocridad intelectual triunfante en las instituciones controladas por el Régimen, lo llevaron a replantear las posibilidades subversivas del lenguaje. Ángel González se anticipó a las evoluciones de la época del desencanto pese a la democratización del país, que no hizo más que fortalecer el sentimiento de potencia mitigada de la palabra para transformar el mundo. Comparte Ángel González con ciertos escritores y artistas un recio escepticismo, pero como no puede ni quiere renunciar a una pulsión creadora ante una realidad que no lo satisface, entonces ve en la postura "antipoética» un dinamismo capaz de evitarle a la poesía un posible agotamiento.

Nos consta que la antipoesía fue para Ángel González su manera de redinamizar el ejercicio de la poesía y sacarla de la clausura ideologizada. De ahí su interés por lo aparentemente anecdótico, lo cotidiano que roza con lo trivial, lo fugaz, lo irrisorio. Se me objetará que, desde que existe la lírica, esta mantuvo un discurso contra la fugacidad, pero con el tiempo sus formas se convirtieron en convencionalismos ya sin atractivo. La antipoesía se presenta entonces como una modalidad abierta, fecunda y con alto poder corrosivo. El caso es que, si su discurso puede abarcar un objeto exterior (el horizonte social, político, cultural), también toma como blanco al propio poeta: este escribe contra su propia sumisión, contra lo que su entorno teje como fuerza de avasallamiento, contra la fatalidad contractual de la lengua. De modo que «antipoesía» es acaso un comodín para designar ante todo el esfuerzo rupturista ante la convención literaria, afán de ruptura sin perder de vista cierto trasfondo realista para que el lector no se quede «aturullado» por oscuras divagaciones, y para que se conserve el necesario grado de complicidad entre el poeta y su lector. Para lograr semejante objetivo, el poeta posmoderno adopta ciertas estrategias como la parodia, la distorsión, la mezcla o cierto hibridismo de los niveles del lenguaje y varias modalidades de la intertextualidad y, por fin, la desacralización del arquetipo del poeta inspirado o demiurgo.

En las distintas poéticas que Ángel González escribió para orientar a sus lectores, hay una que resume ciertos procedimientos característicos de la antipoesía: es «Contra-orden. (Poética por la que me pronuncio ciertos días)». Aparece dentro de una serie de cuatro poéticas que Ángel González enuncia para discriminar entre varias posturas. Después de las consideraciones para enfocar en 
tono humorístico las exigencias de la llamada "poesía pura», pasa a acometer el polo opuesto. La llama "contra-orden» para contraponerla a lo que durante varios decenios fue el canon poético imperante. A la inversa, la "contra-orden» valora lo prosaico, acudiendo por mimetismo al graffiti, a los anuncios callejeros, a todo un material de derribo reciclado para ambientar la preceptiva en un trasfondo urbano:

Esto es un poema.

Aquí está permitido

fijar carteles, tirar escombros, hacer aguas

y escribir frases como:

Marica el que lo lea, Amo a Irma, Muera el... (silencio), Arena gratis, Asesinos, etcétera.

Esto es un poema.

Mantén sucia la estrofa.

Escupe dentro.

Responsable la tarde que no acaba, el tedio de este día, la indeformable estolidez del tiempo (González, 1986: 293).

Esta poesía ganada sobre el lenguaje cotidiano establece una forma de complicidad con el lector menos culto. Pero el poeta no evita, al cerrar el texto, una conclusión más sutil que subraya lo absurdo de la existencia, el asco sartreano frente al desamparo metafísico que cercena la voluntad de vivir. Esta tensión entre lo feo y la consideración irónica que se puede adoptar ante la realidad más trivial acaba por ser un factor creativo que hasta la fecha no tenía carta de ciudadanía en la poesía.

Otra dimensión del mensaje que va en contra del canon poético es la inclusión en el corpus gonzaliano del chiste o chascarrillo, como él decía. Pongamos cinco ejemplos que muestran la variedad de los recursos a que acude el poeta para romper el tono serio que 
se suele asignar a la literatura, aunque siempre existió un espacio para el humorismo:

ESO ERA AMOR

Le comenté:

- Me entusiasman tus ojos.

Y ella dijo:

- Grandes, - ¿Te gustan solos o con rímel?

respondí sin dudar.

Y también sin dudar me los dejó en un plato y se fue a tientas

(González, 1986: 241).

MONÓLOgO INTERIOR

Manolo go

interiormente za

cuando su mujer dice fornica por formica

(González, 1986: 256).

FINAL CONOCIDO

Después de haber comido entrambos doce nécoras, alguien dijo a Pilatos:

- ¿Y qué hacemos ahora?

Él vaciló un instante y respondía

(educado, distante, indiferente):

-Chico, tú haz lo que quieras.

Yo me lavo las manos

(González, 1986: 257).

ESO LO EXPLICA TODO

Ni Dios es capaz de hacer el Universo en una semana.

No descansó el séptimo día.

Al séptimo día se cansó

(González, 1986: 348). 
Dijo:

Comed, este es mi cuerpo.

Bebed, esta es mi sangre.

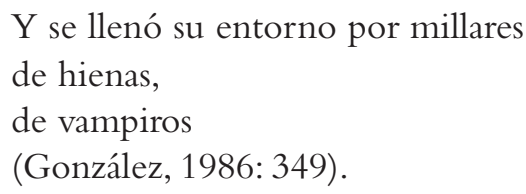

En el primer ejemplo, Ángel González juega con la polisemia de una situación que equipara el encanto de una mujer con el disfrute de un plato estupendamente cocinado. El amplio espectro de uso del verbo "gustar» permite con absoluta normalidad esta equivalencia reforzada por el giro lacónico: «solos o con rímel». Brota el humor negro, en el momento en que se resuelve la situación con el gesto imprevisible y grotesco de la mujer: «me los dejó en un plato y se fue a tientas». La comicidad final se debe a la conservación de la lógica: carente de vista, la amada no puede alejarse más que «a tientas». Después de la evocación de un gesto absurdo por aceptar un pimpante piropo, la conclusión toma las apariencias del buen sentido. La suspensión de la evidencia - que correspondería a un gesto cruel e impensablecomunica al enunciado un cariz absolutamente natural.

El ejemplo segundo tiene un inevitable efecto cómico fundado en la paronomasia:fornica/formica. Pero la confusión puesta en boca de una mujer casada resulta francamente graciosa, ya que revela de parte de ella su ignorancia del sentido exacto de «fornicar», que una mujer de buenos modales no pronunciaría sin sonrojarse si tuviera conciencia del uso culto o vulgar de un latinismo que remite a las relaciones sexuales fuera del matrimonio. En una sociedad de costumbres pudorosas, donde no se hablaba libremente de temas sexuales, la ignorancia léxica de la mujer de Manolo no hace sino recalcar el malestar que afecta a la pareja, ya que el tal Manolo se censura al no intentar traer una indispensable enmienda. El silencio de este «monólogo interior» oculta cierto placer del varón al oír este desliz verbal.

La religión es un tema que aborda Ángel González en un sentido más bien crítico, sarcástico, que incluso podría rozar con la irreverencia en «Invitación de Cristo» (quinto ejemplo), cuando se tornan dicho irrisorio las palabras de la consagración eucarística que acaba por atraer a «millares de hienas, de vampiros». Sin embargo, sería abusivo hablar de una manipulación deshonrosa de la frase evangélica, cuando el poeta se 
atreve a glosar un enunciado simbólico por tomarlo en el sentido literal. Este desplazamiento contribuye a la construcción de un discurso crítico e irónico en torno a un prurito de religiosidad exacerbada que el poeta, por motivos personales, ya no aguanta. Más suave es la inversión del lenguaje del texto-fuente sacado del Génesis en «Eso lo explica todo», cuando el poema dice que después de crear el mundo, Cristo se descansó el séptimo día.Ángel González niega el sentido del séptimo día, dando a entender que el cansancio dejó al Creador agobiado y sin ganas de seguir adelante. Indirectamente el poeta apunta la imperfección de la Creación divina. Pero la formulación casi anodina y avanzada como una broma evita el tono irreverente y casi blasfematorio que habría producido una constante anticlerical. No podemos descartar que esta estrategia amable, no siempre mordaz y tan fina como en «Final conocido", sea una manera de echar tierra entre una crisis espiritual y el agnosticismo naciente del poeta. Más allá del caso personal, semejante discurso acompaña la captación de los primeros signos de una sociedad que inicia su descristianización. Mucho más fino es el ataque, a nivel moral, de "Final conocido», ya que se trata en este caso de la última cena de Cristo reinventada porque comparten la mesa el traidor y el procurador Pilatos. El texto del poema denuncia la excesiva prudencia de Pilatos que no hace nada para evitarle a Cristo la muerte o suavizar su castigo. Imagina Ángel González el detalle trivial de comer «doce nécoras» (la cifra no es anodina y connota la última cena con los doce apóstoles), y ante la pregunta de uno de los comensales (judas?): «- $\mathrm{i} Y$ qué hacemos ahora?», la respuesta, «Yo me lavo las manos», juega con el doble sentido literal y explícito y el sentido figurado de quien no quiere responsabilizarse en un asunto.

Ocurre que, a veces, topamos con un nivel más elaborado de humorismo, porque el autor se apoya en un hipotexto que le sirve como punto de partida. Algo que suena a aforismo, refrán o sentencia puede ser objeto de un desvío semántico. Este procedimiento forma parte de una "escritura imitativa», sin desarrollarse como parodia de un género preexistente; finge adoptar una postura más humilde, sin pretensión literaria. Es interesante por esta razón el "Apotegma» humorístico que Ángel González dedica al personaje de Orfeo; no hay parodia, ni subversión formal; sin embargo el enunciado remite a una situación que arrasa el mito fundador de la poesía lírica: la pérdida irremediable de la amada como fuente del canto. En su formulación lacónica, el «apotegma» de Ángel González parece despedirse del eterno lamento con el cual no quiere confundir su propia práctica. Sigue con esto en la tradición del epigrama para acunar el emblema de una postura acaso insostenible: la razón de la lírica es una aporía. 
No hay otra solución:

si de verdad amas a Eurídice,

vete al infierno.

Y no regreses nunca

(González, 1986: 299).

Lo que prevalece en ciertas composiciones breves gonzalianas es el placer del autor, en busca de la adhesión de un público lector que se reconoce en el propósito mantenido por el poeta. Partiendo de la cuestión de la identidad heracliteana: «Nadie se baña dos veces en el mismo río», Ángel González imagina una serie de variaciones semánticas en las que lo que se predica se aplica a dos mundos opuestos (pobres vs. ricos).Y la gracia de la propuesta consecutiva se debe al contraste no previsible de la deducción entre las propuestas 1 y 2 de las «Glosas a Heráclito»:

1.

Nadie se baña dos veces en el mismo río.

Excepto los muy pobres.

2.

Los más dialécticos, los multimillonarios: nunca se bañan dos veces en el mismo traje de baño.

3.

(Traducción al chino.)

Nadie se mete dos veces en el mismo lío.

(Excepto los marxistas-leninistas.)

4.

(Interpretación del pesimista.)

Nada es lo mismo, nada

permanece.

Menos

la Historia y la morcilla de mi tierra:

se hacen las dos con sangre, se repiten

(González, 1986: 302).

Aunque el punto de partida no obedezca a ninguna lógica: tan solo se supone que para los más desfavorecidos lo más natural es 
algo aún inasequible, mientras que para la gente adinerada la preocupación es buscar el colmo de la frivolidad. Las propuestas 3 y 4 no tienen entre sí relaciones derivadas de la misma matriz léxica. El referente ha cambiado, aunque conserve una proximidad fónica («en el mismo río» / "en el mismo lío»); sin embargo, el poeta inventa un parentesco inesperado al traducir al chino la frase de Heráclito mediante una distorsión. La nueva contextualización que integra una referencia política («excepto los marxistas-leninistas») permite el paso al contexto político español, caracterizado esta vez por un toque de humor negro: «la Historia y la morcilla de mi tierra: / se hacen las dos con sangre». El cierre es tragicómico, porque aúna en una misma conclusión el discurso sobre la guerra civil y sus matanzas y la trivial elaboración de la morcilla. Esta última glosa evidencia con creces la interacción entre el texto y el discurso: se equiparan dentro de una frase única dos realidades con referente social muy alejado, considerando que tienen una idéntica y única naturaleza. La condensación sintáctica (principio del zeugma) permite el brote de la comicidad.

Pero la búsqueda del placer y el gusto por el juego, al saltarse la diferencia referencial, opera una auténtica transgresión del uso normalizado del lenguaje que pide que haya una homogeneidad de contenido para acotar el sentido usual. Una práctica lúdica del lenguaje va en contra del uso convencional «para que nos entendamos». Esta tensión entre texto y discurso no es ajena a la dinámica de la función poética del lenguaje. Lo único que cambia es la tonalidad del mensaje y la convención literaria que aquella pretende servir. De modo que la poesía breve con sabor a chiste o a chascarrillo no hace más que ilustrar una práctica posible del humorismo literario. Esto lo describió meridianamente Genette al insistir en la noción de «juego», el denominador común a todas las prácticas hipertextuales, a todo bricolaje con estructuras lingüísticas preexistentes. La antipoesía tal como la concibe Ángel González es la activación del régimen lúdico del lenguaje, y lleva a una fecunda hibridación del texto. Sobre el particular, Genette escribió: «L'hypertexte à son mieux est un mixte indéfinissable, et imprévisible dans le détail, de sérieux et de jeu (lucidité et ludicité), d'accomplissement intellectuel et de divertissement» (Genette, 1982: 453).

Otra manifestación de una postura posmoderna es la que actualiza el gusto de Ángel González por la parodia, especialmente la que deriva de una práctica del ready made. Son muchos los ejemplos de deconstrucción de un género lírico ya establecido, como su «Égloga» (González, 1986: 251), en la que los recuerdos de colegial 
transforman el paisaje bucólico de los paseos con las monjas en un cuadro henchido de sarcasmos hacia la benevolencia traviesa de las educadoras. El poeta seguirá cultivando este tipo de transgresión con sus «fábulas para animales», invirtiendo el esquema consabido para aleccionar a los humanos. Bajo la pluma del poeta, ahora son los animales quienes pueden perfeccionarse imitando al homo sapiens (González, 1986: 154). En este caso, Ángel González demuestra acudiendo a la antífrasis generalizada que los seres irracionales, si entendieran el lenguaje articulado del hombre, se quedarían pasmados ante los vicios y las aberraciones de la sociedad humana. Pero frente a este tipo de subversión de un género nítidamente identificable, cabe observar las ventajas que saca el poeta del ready made, recuperado en un sentido totalmente lúdico y que capta cualquier lector, habida cuenta de que, en el ejemplo que cito a continuación, el hipotexto es una canción popular conocidísima: «Ese lugar que tienes, cielito lindo, junto a la boca», que ha sido transformado por Ángel González de la manera siguiente:

Ese lugar que tienes,

cielito lindo,

entre las piernas,

ese lugar tan íntimo

y querido,

es un lugar común.

Por lo citado y por lo concurrido.

Al fin, nada me importa:

me gusta en cualquier caso.

Pero hay algo que intriga.

¿Cómo

solar tan diminuto

puede ser compartido

por una población tan numerosa?

¿Qué estatutos regulan el prodigio?

(González, 1986: 251).

En este caso lo cómico surge en distintos niveles: a nivel retórico por la sustitución («junto a la boca» = «entre las piernas»), por la permutación («lugar común» / «lugar íntimo») que origina un doble sentido, con una connotación erótica evidente, por la supresión 
o elipsis de la palabra clave, sugerida por las aliteraciones ("común», "concurrido», «me gusta en cualquier caso», «como", «compartido»), por una nueva sustitución con parentesco fónico («lunar», «lugar», «solar») y a nivel lexemático en la conclusión con un cierre cómico tomado de la jerga administrativa: «¿Qué estatutos regulan el prodigio?». Todo esto amalgamado en un texto muy coherente y de fácil captación lleva a un efecto cómico evidente, que se aprovecha de la tensión entre la letra de la canción que expresa un sentimiento posesivo y excluyente en clara contraposición con el texto del poema. El paso por el ready made nos ofrece la ocasión de ver que la parodia, a pesar de su funcionamiento retórico, no se deja reducir totalmente a la retórica, y es otra cosa que una mera técnica para citar un texto ajeno: llega a ser una práctica más ambiciosa en la que presenciamos, como lo dice Genette, «la transformación lúdica de un texto singular». La transgresión de la coherencia lingüística y estilística por rupturas sintácticas, por conflictos de niveles de lengua, son manifestaciones del ludismo, con el que el poeta pretende establecer la complicidad amena con su lector, haya o no haya una intención satírica. El caso estudiado no contiene ninguna denuncia, malicia sí, ante las relaciones de ambos sexos, con un tinte de buena conciencia juguetona, y al fin y al cabo una manera de derogar el ambiente dulzón de la canción popular. El «¿Qué estatutos regulan el prodigio?» bien podría admitir una interpretación metapoética. El resultado es que el humor derivado de esta «manipulación» permite entrar en la fase constructiva de la parodia, y darle a la misma parodia la categoría de género.

También el imperio del juego preside un breve poema tardío como "Pronóstico»; el texto matriz arranca como un clásico parte meteorológico:

\author{
Mañana \\ las temperaturas más altas \\ apenas llegarán a los quince \\ años que cumplirás un día de estos. \\ Tiempo inseguro, dicen los pronósticos, \\ con toda la razón del mundo en marzo. \\ Tristemente nublados al Oeste, \\ los vientos soplarán del Sur, aviesos, \\ malas noticias a la policía. \\ Probable es que su aliento te levante \\ el ruedo de la falda, \\ y ya veremos (González, 2001: 29).
}


El texto tiene una perfecta homogeneidad, que solo alteran tres rupturas de la lógica semántica: la silepsis: «quince años» cuando se esperaba «quince grados»; un tipo de modalización que normalmente no se justifica de ninguna manera en un parte meteorológico: «tristemente nublados», «vientos aviesos» soplarán «malas noticias a la policía», con inclusión de una metáfora. Semejante desvío es totalmente inesperado, a no ser que se apoye el enunciador en reminiscencias personales y afectivas procedentes de lecturas o películas policíacas que establecen una relación entre las noches de plenilunio y los crímenes sexuales. Pero el poeta decidió limitar los efectos funestos del viento a una fugitiva visión erótica: «Probable es que su aliento te levante / el ruedo de la falda, / y ya veremos». Esta situación tiene antecedentes lorquianos conocidos, con el «viento hombrón» algo lúbrico que levantó el «polisón de nardo» de la bella niña. Más allá de la llaneza del poema breve gonzaliano y su amena alusión erótica, el gusto por la parodia puede ser revelador de posturas culturales, sociales, políticas, como lo mostró Bakhtin en su análisis de lo carnavalesco. Para liberarse de todas las opresiones sociales, cualquiera que sean las épocas y los regímenes políticos, el hombre acude a la risa o la irrisión. Y los artistas cultivaron esta inclinación desde las épocas más remotas para acompañar los acontecimientos festivos. La llamada "antipoesía» no hace sino prolongar una vertiente jocosa y festiva de raigambre antropológica. Lo que comentábamos anteriormente a propósito de poemas que aluden a personajes bíblicos o gestos del ritual católico tuvo su manifestación desde la Edad Media con su catecismo jocoso y sus caricaturas de Judas que reparte besos a todos los vecinos del lugar, o de Pilatos que trae jofaina para «lavarse las manos».

Ocurre que Ángel González usa los extremos de la caricatura para describir de manera exacta una situación degradada o insoportable. Si acude en el caso de "Pretexto» a la hipérbole, considerándose como hijo de una época absurda y cruel hasta transformarse en un nuevo Drácula o vampiro, la conclusión no lleva a la desesperanza ni al nihilismo. Al contrario, partiendo de lo negativo, el poeta expresa la conservación de un pujante vitalismo, salvado por el distanciamiento humorístico:

No fueron tiempos fáciles, aquellos.

Me amamantó una loba.

¿Quién si no?

Yo no tengo la culpa

de haber bebido 
desde tan joven tanta sed de sangre,

tanto deseo de morder la vida,

tanto amor (González, 1986: 389).

La desgracia y el salvajismo no acaban con el deseo de libertad y fraternidad; el caso es que de momento solo encuentra salida a partir de «las riendas sueltas» del lenguaje, y el brote de lo imaginario así liberado. El giro que operó Ángel González con su producción poética desde Procedimientos narrativos activa en esta forma de «des-poetización» un proceso dinámico de re-creación. Coincide la práctica del poeta con las intuiciones de Hugo Friedrich, al señalar en su Structure de la poésie moderne las nuevas categorías del discurso poético que nacen con la modernidad:

Connaitre la poésie moderne implique que l'on invente des catégories nouvelles qui permettront de la décrire. Il est impossible d'échapper à un fait confirmé par toute la critique moderne: les catégories qui s'imposent sont essentiellement négatives. Il est cependant de la plus grande importance que ces catégories ne soient pas utilisées de manière dépréciative, mais, au contraire, comme de simples définitions (Friedrich, 1999: 20).

La contraposición de elementos anecdóticos con tradiciones literarias de más alto vuelo acaba por definir una línea de conducta para la creación que se abre al mundo de la posmodernidad, en el que las fronteras genéricas son más que porosas; asistimos en la literatura en general a una forma de hibridación de los géneros en conformidad con la percepción del mundo que el escritor intenta comunicar. La invención misma como título de un poemario, Prosemas o menos (1985), apunta con el neologismo "prosema» un modo de organizar lo poemático fuera de las normas habituales que encauzan la poesía y la prosa. Gonzalo Sobejano tuvo palabras elogiosas para saludar el llamado «prosaísmo» de Ángel González, dudando sobre la palabra adecuada para designar esta fluidez propia del lenguaje hablado ordinario («prosismo» permite evitar la connotación negativa de "prosaísmo»). Pero, sobre todo, el crítico quiso poner de relieve una particularidad de la poesía gonzaliana que asimila la transparencia y la transitividad propias de la lengua vernácula, sin renunciar a la plusvalía del significante literario. Gonzalo Sobejano ve en los prosemas de Ángel González un esfuerzo ético para no caer en la trampa de la ilusión: 
Con la poesía moderna adviene en varias formas un prosismo o prosásmo deliberado: temáticamente, por el lado romántico, el mal y la fealdad, y por el lado realista, la insignificancia; formalmente, la abertura de la lengua poética hacia los medios de expresión de la prosa. Cualquier elemento de esta (en contenido, en expresión) puede considerarse desde el punto de vista de la poesía como negatividad, y de lo que se trata es de asumir esta negatividad. Salvación de la prosa no porque el mal aparezca dignificado como bien, lo feo como bello, lo insignificante como significante, sino porque mal, fealdad, insignificancia son verdad (Sobejano, 1987: 25-26).

Si podemos rastrear en la poesía de Ángel González numerosos prosaísmos: «Ni Dios es capaz de hacerlo» (1986 : 77), «sé lo que es esperar» (ibíd.: 83), «De vosotros / los jóvenes, / espero / no más cosas grandes que las que realizaron / vuestros antepasados» (ibíd.: 110), «Elena despertó a las dos y cinco, / abrió despacio las contraventanas» (ibíd.: 195), etc., esto no significa que el poeta haya optado por un rebajamiento de la forma literaria, ni mucho menos, porque pronto recupera el signo literario al introducir una sobresignificación que da al enunciado su tinte poético. Bien puede acá o allá utilizar un giro conversacional y hacerse con un retruécano («sin contar con Dios Padre - y los restantes», como quien dice los santos orantes), atenuar lo grave con el eufemismo («estirarse definitivamente»), y el discurso se encamina inexorablemente hacia el hallazgo de su desenlace: «vivo / [...] / mi hora la terrible: / la que aún no ha sonado» (ibíd.: 77).

La antipoesía es también una postura que permite rechazar la antinomia poesía vs. relato. Ángel González adopta con sus Procedimientos narrativos una actitud antimallarmeana, pues Mallarmé repudiaba lo anecdótico, lo narrativo, lo didáctico («l'universel reportage») para acceder a lo esencial. Pero no se ve por qué la búsqueda de lo esencial no se encontraría en la expresión de lo fugaz, lo provisional, lo intrascendente, cuando todo aquello no es más que la otra cara de las preocupaciones más duraderas y profundas. La «poética antipoética» de González niega el ascetismo etéreo de Mallarmé para sustituirlo por una exigencia existencial. La época que le tocó vivir (la era franquista), acrecentada acaso por el desencanto que surgió tras el hundimiento de las ideologías de izquierda, contemporáneas de las promesas no cumplidas de la democratización en España, configuran una cosmovisión escéptica que se resuelve en la erosión de las creencias de todo tipo y, por lo que toca 
a las formas artísticas, en un desguace de lo canónico. A partir de este estado de crisis, el poeta se involucra en una forma de escritura fragmentada, parcial, centrada en el análisis de situaciones concretas y bien acotadas. Su incursión en la intertextualidad transgenérica propia de la posmodernidad diseña los contornos de un discurso que obedece a nuevas pautas de conocimiento. La antipoesía instaura el nuevo paradigma de la belleza, o mejor dicho la no-coincidencia entre belleza y arte. Lo bello ya no es forzosamente un elemento central del arte; ahora se nutre de ingredientes varios, abandonando la noción kantiana de buen gusto para adscribirse a estéticas transgenéricas. El amor de Ángel González por la parodia significa también que la posmodernidad no rechaza todo el legado de la tradición, ya que este le sirve de imprescindible palanca para definir su propia trayectoria con vistas a desplazar los límites que impone cualquier canon. 


\section{BIBLIOGRAFÍA}

Friedrich, Hugo (1999). Structure de la poésie moderne, Paris, Librairie

Générale Française (Coll. Livre de Poche/Références).

Genette, Gérard (1982). Palimpsestes, Paris, Seuil.

GonZÁLez, Ángel (1980). Poemas, ed. del autor, Madrid, Cátedra.

- (1986). Palabra sobre palabra, Madrid, Seix Barral.

- (2001). Otoños y otras luces, Barcelona, Tusquets.

Sobejano, Gonzalo (1987). «Salvación de la prosa, belleza de la necesidad en la poesía de Ángel González», en Simposio-homenaje a Ángel González, eds. Susana Rivera y Tomás Ruiz Fábrega, Madrid, José Esteban.

VÁsquez Rocca, Adolfo (2012). «Nicanor Parra: antipoemas, parodias y lenguajes híbridos. De la antipoesía al lenguaje del artefacto", Nómadas. Revista Crítica de Ciencias Sociales y Jurídicas, número especial, http://dx.doi.org/10.5209/rev_NOMA.2012. 41775. 